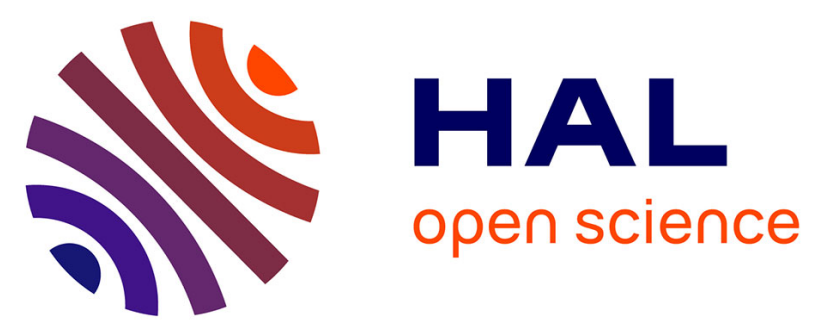

\title{
The changing role of the senses in food choice and food intake across the lifespan
}

\author{
Sanne Boesveldt, Nuala Bobowski, Keri Mccrickerd, Isabelle Maître, Claire \\ Sulmont-Rossé, Ciarán G. Forde
}

\section{- To cite this version:}

Sanne Boesveldt, Nuala Bobowski, Keri Mccrickerd, Isabelle Maître, Claire Sulmont-Rossé, et al.. The changing role of the senses in food choice and food intake across the lifespan. Food Quality and Preference, 2018, 68, pp.80-89. 10.1016/j.foodqual.2018.02.004 . hal-02623932

\section{HAL Id: hal-02623932 \\ https://hal.inrae.fr/hal-02623932}

Submitted on 18 Feb 2021

HAL is a multi-disciplinary open access archive for the deposit and dissemination of scientific research documents, whether they are published or not. The documents may come from teaching and research institutions in France or abroad, or from public or private research centers.
L'archive ouverte pluridisciplinaire HAL, est destinée au dépôt et à la diffusion de documents scientifiques de niveau recherche, publiés ou non, émanant des établissements d'enseignement et de recherche français ou étrangers, des laboratoires publics ou privés.

\section{(1) (1) $\$$}

Distributed under a Creative Commons Attribution - NonCommercial - NoDerivatives| 4.0 


\section{The Changing Role of the Senses in Food Choice and Food Intake across the Lifespan}

Sanne Boesveldt ${ }^{1}$

Nuala Bobowski ${ }^{2}$

Keri McCrickerd ${ }^{3}$

Isabelle Maître ${ }^{4}$

Claire Sulmont-Rossé ${ }^{5}$

Ciarán G. Forde F,6* $^{3,6}$

\section{Affiliations:}

${ }^{1}$ Division of Human Nutrition, Wageningen University, Wageningen, the Netherlands

${ }^{2}$ Department of Nutrition \& Exercise Sciences, Henrietta Schmoll School of Health, St.

Catherine University, 2004 Randolph Avenue, St. Paul, MN 55105, USA

${ }^{3}$ Clinical Nutrition Research Centre, Singapore Institute for Clinical Sciences, Agency for Science, Technology and Research (A*STAR), Singapore

${ }^{4}$ USC 1422 GRAPPE, Univ. Bretagne Loire, Ecole Supérieure d'Agricultures (ESA)-INRA, SFR 4207 QUASAV, 55 rue Rabelais 49007 Angers, France.

${ }^{5}$ Centre des Sciences du Goût et de l'Alimentation, AgroSup Dijon, CNRS, INRA, Univ. Bourgogne Franche-Comté, F-21000 Dijon, France

${ }^{6}$ Department of Physiology, Yong Loo School of Medicine, National University of Singapore, Singapore

*Author to whom correspondence should be addressed:

Dr. C.G. Forde

Clinical Nutrition Research Centre, Singapore Institute for Clinical Sciences, Yong Loo Lin School of Medicine, National University of Singapore, 14 Medical Drive \#07-02, MD 6 Building, Singapore 117599.

Email: ciaran_forde@sics.a-star.edu.sg 


\begin{abstract}
:
Sensory perception begins before birth and enables us to interpret the biological relevance of stimuli in our near environment. In early life, the senses play a crucial role in informing acceptance and rejection of foods and beverages. Food preferences develop with experience based on associations formed between a foods flavour and the consequence of its consumption. In adulthood the role of the chemical senses is often simplified into simple 'likes' and 'dislikes', but recent evidence highlights a more functional role in guiding eating behaviours and nutrition. A food's perceptual properties are important for the detection of its nutrient content and through this, guide not only food choice but also habitual energy selection and consumption behaviour. As we age and the prevalence of chronic disease increases, sensory acuity often declines for taste, smell and texture perception, and this can have an impact on food perception, preference and food intake. This creates an opportunity to apply an understanding of sensory influences on choice and intake to stimulate appetite during periods where nutrient intakes may become compromised. This paper summarises current knowledge of the changing role of the senses during infancy and early childhood, through to adulthood, older age and illness. The aim is to highlight opportunities to improve health and wellness through a better understanding of how sensory factors can influence eating behaviours and nutrition at key time points across the lifespan.
\end{abstract}

Keywords; Sensory perception, children, food choice, preference, obesity, food intake, elderly, cancer, neurodegenerative disease 


\section{(1.0) Introduction:}

From the third trimester of pregnancy onwards, the chemical senses detect stimuli in our near environment and initiate our understanding and navigation of the world around us. In early life we experience our first exposure to the basic tastes and smells in our food environment, and through this develop knowledge about what is safe, enjoyable and rewarding to eat. Food choice and ingestion are important learned behaviours built on the relationship between sensory information and post-ingestive experience of fullness and satisfaction. Food has no nutritional value until it has been chosen and consumed, and repeated consumption over time will depend on the acceptability of this experience, which changes with increased age and illness. From infancy, taste, smell, and texture play a central role in the palatability of first foods and these cues continue to stimulate our desire to eat, alongside vision and audition. As the food environment becomes more complex, a food's taste quality and texture provide valuable cues about the potential post-ingestive consequences of consumption, such that these cues have a functional role to play in everyday energy selection and appetite regulation. For example, food odours stimulate our appetite and influence our food choices, while food texture can moderate energy intake through its impact on eating rate. For equally liked foods, subtle differences in sensory quality and intensity can influence eating behaviours and the energy consumed to fullness. Understanding how these food sensations shape eating behaviours linked to overconsumption will be central to the development of food based approaches to prevent noncommunicable chronic conditions such as obesity and type-2 diabetes across the lifespan.

The sensory systems begin to decline in acuity in older consumers, and this can impact the relative contribution each sense makes to the perceptual response to food and beverages as we age. Older consumers are the most heterogeneous group in terms of their perceptual abilities and dietary experience, and these perceptual changes occur at a time when nutrition is essential for maintaining good health and immune function. Our understanding of these sensory changes has improved, but there remains a need to apply this understanding to improve food acceptability and stimulate food intake in an increasingly vulnerable population. The prevalence of chronic illness and disease increases with age, leading to extensive changes in sensory perception. The pathology and treatment of conditions such as cancer and neurodegenerative diseases like Alzheimers disease can also influence perception and appetite. Changes in the sensory systems 
during these conditions can also be used for early diagnosis of these conditions and sensory based approaches to stimulate appetite and food intake can be applied to reduce malnutrition during the treatment of these illnesses.

The current paper presents an overview of the changing role of the sense in informing food choice and intake and stimulating appetite during infancy, childhood, adulthood, older age and during chronic disease states.

\section{(2.0) Learning to like a healthier diet: Flavour preference development in infancy and childhood}

Taste preference is one of the strongest motivating drivers of food choice and intake throughout the lifespan, but is perhaps most evident early in life, when infants and children eat what they like and reject what they dislike. Taste preferences are inborn but are modifiable with sensory experience, and the plasticity of the taste system presents an opportunity to promote a healthier dietary intake (Mennella, 2014). Although there are at least five basic taste primaries (sweet, salty, sour, umami and bitter), we focus primarily on sweet, salty and bitter because these tastes are arguably most salient to children's dietary intake, associated with the ingredients and foods that children consume in quantities that exceed (e.g. added sugars and salt) and fail to meet (e.g. vegetables) recommended levels of intake (Drewnowski \& Rehm 2014; Jackson et al., 2016; Kim et al., 2014).

Liking for both sweet and salty tastes is thought to reflect basic biological need: sweet taste signals the presence of calories, attracting the child to mother's milk and nutrient-dense fruit; and salty taste, the sodium and minerals required in small amounts for physiological functioning. Liking for both tastes is reflected in the ingestive behaviour of infants and children. Within hours of birth, new-borns are not only able to discriminate sweetness from other taste qualities (Rosenstein \& Oster, 1988) and discriminate between different concentrations of sweetness (Nowlis \& Kessen, 1976), but they also exhibit a positive hedonic response to sweet taste as evidenced by facial reactivity (Rosenstein \& Oster 1988; Steiner, 2001), increased strength and frequency of sucking response (Maone et al., 1990) and increased ingestion of a sweetened solution compared to water (Desor et al., 1973). Infants are indifferent to salty taste at birth 
(likely due to post-natal maturation of taste receptors), but by 4 months of age will ingest more saline solution than water (Beauchamp et al., 1986), and will consume more salted than unsalted foods as early as 31 months (Beauchamp \& Moran, 1984; Duffy, 2013). Beyond infancy, agerelated comparisons of salty and sweet taste preferences between children and adults consistently illustrate that children prefer greater concentrations of both salt (Beauchamp \& Cowart, 1990; Mennella et al., 2014) and sucrose (de Graaf \& Zandstra, 1999; Mennella \& Bobowski, 2015) than do adults. This finding was recently extended to both fructose (Mennella et al., 2017) and sucralose (Bobowski \& Mennella, 2017), with the latter highlighting children's proclivity for sweetness even when decoupled from calories.

Unlike both sweet and salty tastes, disliking for bitter taste is thought to serve a protective function in preventing the child from ingesting anything potentially poisonous or toxic (Glendinning, 1994). After exposure to a bitter taste such as quinine, infants will display negative facial reactions, (Rosenstein \& Oster 1988), and elicit decreased suckling response and ingestion of bitter-tasting solutions (Kajiura et al., 1992). In addition to their heightened preference for sweetness, children are also more sensitive to some bitter tastes than adults. Individual differences in perception of propylthiouracil (PROP) are driven by the TAS2R 38 bitter taste receptor gene wherein individuals with the bitter-sensitive genotype (PP) perceive PROP as more bitter than either heterozygotes (AP) or those with the bitter-insensitive genotype (AA) (Bufe et al., 2005). In an examination of age-related differences in detection thresholds for PROP, when matched for genotype, AP and PP children were significantly more likely to detect PROP at lower concentrations than were adults (Mennella et al., 2010).

\section{(2.1) Children eat what they like and like what they know: The importance of repeated sensory exposure}

Though inborn taste preferences could set the stage for a poor dietary intake, particularly within the context of our modern-day food supply, liking for novel or previously disliked tastes and flavours can be learned using a combination of associative learning and mere exposure (the disappearance of neophobia) through repeated sensory experience based on the simple tenet that what is familiar is appropriate, and what is appropriate is accepted (Sullivan \& Birch, 1990; Cooke, 2007). This process begins before birth and continues during weaning as flavours are 
transferred through the mother's diet to both amniotic fluid (which the foetus actively swallows and tastes) and to breastmilk, which increases the infant's exposure to and acceptance of those flavours (Mennella et al., 2001). During infancy and childhood, the same principle of learning applies both in teaching the child to accept new foods (Birch \& Fisher, 1998) and in teaching the child about taste appropriateness and whether a food "should" taste salty or sweet, and how salty or sweet that food should taste (Sullivan \& Birch, 1990), with 5 to 10 exposures typically sufficient to increase hedonic response (Birch \& Fisher, 1998). Whether the impact of early exposure on dietary intake endures more broadly in adult dietary patterns throughout the lifespan remains unknown; however, fruit and vegetable variety consumed by children ranging in age from 2 to 8 years is predicted by breastfeeding (Burnier et al., 2011), early exposure to fruit and vegetables (Skinner et al., 2002; Cooke et al., 2004), and parental intake of fruit and vegetables (Cooke et al., 2004). Additionally, in two separate studies, children exposed during infancy to sugar water (Beauchamp \& Moran, 1982) or to starchy table foods high in sodium (Stein et al., 2012) were more likely to maintain preference for sucrose solutions, and to exhibit behaviours such as eating salt directly from a shaker, respectively, than children who were not exposed.

\section{(2.2) Identifying opportunities to increase acceptance of a healthier diet}

Our food environment is one that incentivizes intake of salty and sweet food products high in salt and sugar are often convenient, inexpensive (Drewnowski \& Specter 2004), and available in abundance. Additionally, these products tend to be highly palatable, especially to children, who with heightened preferences for sweet and salty tastes and increased sensitivity to some bitter tastes, may be more likely to avoid many of the foods that contribute to high nutrient density and dietary health. Though a significant change in the dietary behaviour of all children will first require that foods like fruits and vegetables are widely accessible, a child's acceptance of these foods can be significantly increased by encouraging parents to incorporate a variety of fruits and vegetables into their own diets and to expose their children as early as possible. This process can begin in utero, and continue during breastfeeding, and through repeated exposure to appropriate solid foods during weaning.

A continued focus on basic research to further elucidate associations between the child's preferences, the sensory properties of foods, and eating behaviour is needed, including the 
potential impact of an increased prevalence of low-or-no-calorie sweeteners in the food supply (Sylvetsky et al., 2012); and an examination of whether children's salty and sweet preferences can be shifted downwards following repeated exposure to less salty- and sweet-tasting foods. In addition, future research should focus on discerning to what degree taste preferences developed in infancy and early childhood endure into adolescence and adulthood; as well as moving beyond taste hedonics to consider how early experience with different textures could influence the development of children's eating behaviours (Werthmann et al., 2015; Fogel et al., 2017a, 2017b), including intake of the types of foods older children and adults accept and choose to consume.

\section{(3.0) Sensory influences on food intake control during adulthood}

Over the thousands of meals and snacks consumed, adults have learned to like a range of foods, through exposure to a wide variety of different tastes, smells and textures. As in childhood, palatability and food preferences are still a major determinant of food choice and intake; adults also eat more of the foods they like the flavours of, and rarely consume foods they do not like. As such, palatability is often considered the most significant sensory driver of overconsumption across the lifespan (Sorensen, Moller, Flint, Martens, \& Raben, 2003). Yet the capacity for a food or beverage to influence appetite control is dependent on a complex integration of preingestive cognitive and sensory cues alongside later post-ingestive and post-absorptive nutrient signals (Blundell et al., 2010). With experience, associations between the early sensory experience of eating and the post-ingestive consequence come to signal when, what and how much to eat, beyond simply hedonic evaluation, and these sensory signals can impact a range of eating behaviours captured in adulthood. 


\section{(3.1) Taste and aroma effects on food choice and meals size}

The sensory experience of eating is multifaceted and each component has the potential to influence appetite control in different but interrelated ways. Even before a food can be identified visually, ambient food odours can signal the presence of edible foods in the near environment. Whether perceived or not, familiar food odours appear to direct attention towards food sources and trigger specific appetite for the cued food (Gaillet-Torrent, Sulmont-Rossé, Issanchou, Chabanet, \& Chambaron, 2014; Gaillet, Sulmont-Rossé, Issanchou, Chabanet, \& Chambaron, 2013; Ramaekers, Boesveldt, Lakemond, Van Boekel, \& Luning, 2014, Proserpio et al. 2017). Odours of typically high energy dense foods, like pizza or fresh cookies, may promote increased food intake in particularly sensitive individuals including those with overweight (Ferriday \& Brunstrom, 2008, 2011; Tetley, Brunstrom, \& Griffiths, 2009, Zoon, De Graaf and Boesvedlt 2016) or among those actively restricting their food intake (Coelho, Polivy, Peter Herman, \& Pliner, 2009), though not always (Zoon, He, de Wijk, de Graaf, \& Boesveldt, 2014). Once food enters the mouth, however, equally pleasant but more intense or complex retro-nasal aroma release profiles can reduce bite-size and enhance feelings of fullness (de Wijk, Polet, Boek, Coenraad, \& Bult, 2012; Ramaekers, Luning, et al., 2014; Ruijschop, Boelrijk, Burgering, de Graaf, \& Westerterp-Plantenga, 2010; Ruijschop, Boelrijk, de Ru, de Graaf, \& WesterterpPlantenga, 2008), but again with little or no impact on the size of the meal consumed.

Unlike olfaction, gustation is a proximal sense that requires direct contact with food stimuli in the mouth, and is a more influential contributor to meal size. Though sweet and salty tastes are known drivers of palatability and increased food intake (Sorensen et al., 2003), when the intensity of these tastes are varied within a single food or meal, independent of palatability, adults tend to eat about $9 \%$ less of the more intense tasting meal and feel more satiated compared to the less intense but equally liked version (Bolhuis, Lakemond, de Wijk, Luning, \& de Graaf, 2011, 2012; Lucas \& Bellisle, 1987; Vickers \& Holton, 1998; Vickers, Holton, \& Wang, 2001; Yeomans, 1998). Though this effect is small, and possibly diminished when a person is hungry (Bolhuis, Lakemond, de Wijk, Luning, \& de Graaf, 2010), a more intense taste quality is thought to reduce meal size by providing a stronger signal for the presence of nutrients in a food (Bolhuis et al., 2011). However, the large variation in individual preferences for taste and flavour intensities, alongside the negative health impact of overconsuming certain tastants, 
like sodium, currently limit the practical application of using increased taste intensity to enhance the satiating power of everyday meals.

However, the use of low-or-no-calorie sweeteners (LNCS) to maintain the sweet taste of sugarreduced soft drinks is one example of how palatable taste cues have been applied to food products to reduce energy intake, primarily through acceptance of an energy-diluted diet. Despite concerns that decoupling sweet taste from calories in this way can impair some of the learned mechanisms central to appetite control, sustained consumption of LNCS beverages in place of sugar-sweetened versions is linked to reduced daily energy intake and body weight in adults with overweight or obesity (Rogers et al., 2015). This is because people consuming these reduced energy foods rarely fully compensate for the 'missing' calories if the product's original sweet oro-sensory characteristics are well maintained, particularly for liquids (Almiron-Roig et al., 2013). Whether similar reductions in intake can be achieved for more complex food matrices remains a significant challenge for food producers tasked by the negative impact small reductions to a product's sugar or fat content can have on a reformulated food or beverages structure and sensory profile.

\section{(3.2) The impact of food texture on eating rate and appetite control}

Food texture has a particularly unique capacity to influence appetite control mechanisms. Firstly, texture influences beliefs about the potential satiating power of a food, which are an important determinant of portion selection and intake (Brunstrom, 2014). Foods and beverages perceived to be thicker and chewier are expected to be more filling and hunger supressing than versions without these characteristics (Forde, Leong, Chia-Ming, \& McCrickerd, 2017; Hogenkamp, Stafleu, Mars, Brunstrom, \& de Graaf, 2011; McCrickerd, Chambers, Brunstrom, $\&$ Yeomans, 2012). Moreover, foods remembered to be creamy are believed to be more satiating (McCrickerd, Lensing, \& Yeomans, 2015), implying that these beliefs are learned with experience and functional before consumption. Once a food is being consumed, certain textures take more time to be processed in the mouth. Harder and chewier foods are eaten at a slower rate than softer foods and beverages, often requiring smaller bite sizes, more chewing and spend more time in the mouth before swallowing (Forde, Lim, Leong, Chia , \& McCrickerd, 2016; Forde, van Kuijk, Thaler, de Graaf, \& Martin, 2013a; Viskaal-van Dongen, Kok, \& de Graaf, 
2011). Importantly, integrating harder, chewier and thicker food textures to foods or beverages can reduce meal size by $10-30 \%$ compared to similarly liked softer or less viscous versions (Bolhuis et al., 2014; Forde, van Kuijk, Thaler, de Graaf, \& Martin, 2013b; Karl, Young, Rood, \& Montain, 2013; Zhu, Hsu, \& Hollis, 2013; Zijlstra, de Wijk, Mars, Stafleu, \& de Graaf, 2009; Zijlstra, Mars, de Wijk, Westerterp-Plantenga, \& de Graaf, 2008; Zijlstra, Mars, et al., 2009), both independently and in combination with reductions to other important drivers of meal size: energy density and portion size (McCrickerd, Lim, Leong, Chia, \& Forde, 2017). Calorie-forcalorie, 'slower' food structures are often experienced as more satiating after consumption than 'faster' semi-solid and liquid ones, due to a combination of greater expected fullness and modified cephalic phase responses, gastrointestinal processing and transit time, and subsequent excursion of blood glucose and gastrointestinal hormones (Dhillon, Running, Tucker, \& Mattes, 2016).

Overall, a better understanding of the multifaceted influence that the sensory experience of eating can have on appetite control highlights an opportunity to design foods and beverages that promote stronger appetite sensations for the same or fewer calories consumed in a given meal, beverage or snack. With this in mind, the sensory experience of eating should be considered as a functional and modifiable feature of the foods we consume (McCrickerd \& Forde, 2016). Understanding whether sensory modifications to food texture in particular can be applied to promote the satiating power of foods, both alone and in combination with other dietary modifications (e.g. energy density dilution), is a promising avenue for exploration in the development of foods that promote improved appetite control, acceptance of a healthier diet and/or weight management. With this in mind, it is important to consider how our perceptual abilities and nutrition needs continue to change as we age, and where concerns around energy intake reductions might begin to take a back seat to changes in sensory acuity and the need for foods designed to improve specific aspects of under-nutrition instead.

\section{(4.0) Sensory changes with age and impact on appetite and food intake}

Ageing is accompanied by a deterioration in the acuity of taste and smell perception. For olfaction, the literature shows an increase of odour detection thresholds in older people (Stevens \& Dadarwala 1993), a decrease in perceived odour intensity of supra-threshold concentration 
(Stevens, Plantinga \& Cain, 1982; Stevens, Bartoshuk \& Cain, 1984; Koskinen \& Tuorila, 2005) and a decrease in the ability to distinguish between odours (Kaneda, Maeshima, Kobayakawa, Ayabe-Kanamura \& Saito, 1998; Sulmont-Rossé et al., 2015). Several authors have also demonstrated a decline in odour identification and recognition performance, even among healthy older adults not suffering from dementia (identification: Doty, Shaman, Appelbaum, Giberson, Siksorski \& Rosenberg, 1984; Larsson \& Bäckman, 1993; Murphy, Schubert, Cruickshanks, Klein, Klein \& Nondahl, 2002; Koskinen, Kälviäinen \& Tuorila, 2003a; Fusari \& Ballesteros, 2008; recognition: Cain \& Murphy, 1987; Stevens, Cain \& Demarque, 1990; Murphy, Cain, Gilmore \& Skinner, 1991). In terms of gustation, Methven, Allen, Withers and Gosney (2012) showed that older adults display higher detection thresholds for saltiness and sourness in $80 \%$ of studies reviewed, and for bitterness and sweetness in $70 \%$ of studies reviewed. Perceived taste intensity at supra-threshold levels was found to be significantly lower for older adults in $64 \%$ of the studies and identification thresholds were reported to be higher for older adults in $94 \%$ of the studies. Very few studies have explored the ability of older adults to distinguish between various taste intensities. A significant age-related decline in taste acuity has been observed in water solutions (Mojet, Heidema \& Christ-Hazelhof, 2003), but not in real food (Mingioni et al., 2017; Mojet et al., 2003), questioning the real-world impact of these changes on food perception and enjoyment.

However, beyond the overall effect of age on chemosensory abilities, ageing is accompanied by inter-individual variability in olfactory performance scores and, to a lesser degree, in taste performance scores (Stevens \& Dadarwala 1993; Thomas-Danguin et al. 2003; Koskinen \& Tuorila, 2005; Laureati et al. 2008; Sulmont-Rossé et al., 2015). In the French Aupalesens survey ( $\mathrm{n}=559,>65$ yo), $43 \%$ of the sample presented well-preserved olfactory and gustatory abilities, whereas $21 \%$ presented a moderate impairment. Of the sample, $33 \%$ presented wellpreserved olfactory abilities but strong impairment in gustatory ability, and only $3 \%$ were nearly anosmic (Sulmont-Rossé et al., 2015). These results clearly demonstrate that losing the senses of smell and taste with age does not always result in profound overall changes in perceptual ability. In fact, quite a large sample of respondents were still able to perceive the odours and tastes almost as well as younger people. 


\section{(4.1) Causes for chemosensory loss in elderly people}

What could explain this large inter-individual variability in sensory sensitivity among the elderly population? Figure 1 displays a scheme of the different factors liable to have an impact on olfactory capacities in the elderly. A first source of variability could be related to genetic factors. Even in adulthood, some people perceived odours better than others due to differences in their olfactory receptors. However, genetic inheritance alone cannot account for the wide variation in smell ability apparent in aging. A second source of variability stems from past exposure to environmental pollutants (exposure to metals, dust, organic compounds, etc.) in a professional context, current smoking, as well as history of nasal problems, head trauma, strokes and endocrine disorders, all of which may contribute to a decline in odour sensitivity (Amoore, 1986; Corwin, Loury \& Gilbert, 1995; Murphy et al., 2002).

Ageing takes a toll on biological tissues and physiological functions. Ageing is accompanied by the drying of the olfactory mucosa, modifications in the flow and composition of saliva, changes in cell membranes leading to the impaired functioning of ion channels and taste receptors, slower turn-over of sensory cells, and decrease in the speed of the nervous signal (Larsson 1996; Vandenberghe-Descamps et al., 2016). Importantly, ageing is associated with an increased prevalence of pathological events which contribute to declines in chemosensory perception, either directly, as is the case for neuropathological diseases that are known to have an impact on olfactory perception (Murphy et al., 2002; Doty, 1991; Imoscopi, Inelmen, Sergi, Miotto \& Manzato, 2012; Schubert et al., 2012; Henkin, Levy \& Fordyce, 2013), or indirectly, through the consumption of drugs. In this regard many medications are known to affect smell or taste perception (Schiffman, 1991, Doty \& Bromley, 2004, Henkin et al., 2013). These results imply that decline in chemosensory perception may not be inevitable to the aging individual and that factors secondary to aging, such as poor health status or cognitive decline, may contribute to deficits in odour and taste sensitivity beyond the effect of age per se (Griep, Mets, Collys, Vogelaere, Laska \& Massart, 1997; Mackay-Sim, Johnston, Owen \& Burne, 2006; SulmontRossé et al., 2015). 
Figure 1. Review of the factors liable to account for the large inter-individual variability observed in the elderly population for olfactory capacities. These factors included genetic factors, factors related to the past life (life-style, health history) and factors related to ageing (physiological ageing, pathological ageing). Such factors could have a direct impact on olfactory abilities (e.g., ageing of biological tissue) or an indirect impact (e.g., within the course of ageing, the onset of a disease will result of taking drugs, which in turn impairs olfactory perception).

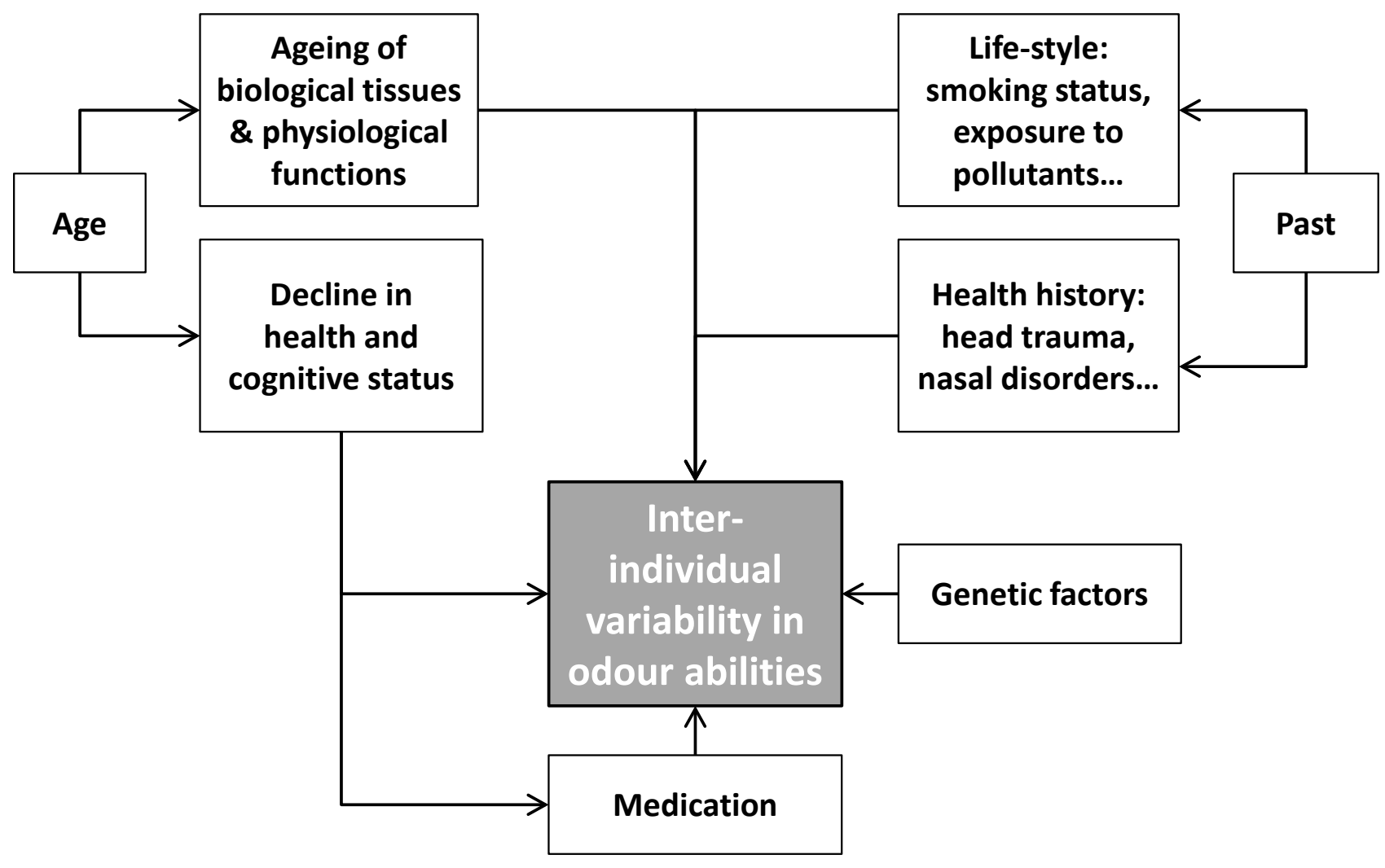




\section{(4.2) Advances in strategies to maintain eating pleasure despite chemosensory loss}

To date, strategies to compensate for loss in chemosensory abilities with ageing have mainly explored flavour enhancement, which has been hypothesized to compensate for the decline in odour and taste perception. However, to date this strategy has provided mixed results (see Table 1 for a review). Mathey, Siebelink, de Graaf, and van Staveren (2001) observed that adding flavourings to the protein part of a meal led to an increase in bodyweight of about $1 \mathrm{~kg}$ after 16 months of intervention in a nursing home. However, when this study was replicated by Essed, van Staveren, Kok, and de Graaf (2007), this effect was no longer present. In fact, a review of the literature shows that enhancing food flavour seldom increases food intake in the elderly. Furthermore, in almost all the studies that have assessed the impact of flavour enhancement on food intake in the elderly, flavour compounds and final concentration of the compounds in the foods were chosen without consulting the target population, namely the elderly people (SulmontRossé, Maître \& Issanchou, 2010). It is possible that the flavour enhanced foods do not fit an individual's expectations or preferences, based on the personal nature of food preferences and the heterogeneity of chemosensory decline within this population. 
Table 1: Review of studies on the impact of flavor enhancement on food intake in elderly people

\begin{tabular}{|c|c|c|c|c|c|c|c|c|}
\hline Reference & $n^{1}$ & $\mathbf{A g e}^{2}$ & $\begin{array}{l}\text { Popu- } \\
\text { lation }^{3}\end{array}$ & $\begin{array}{l}\text { Study } \\
\text { design }^{4}\end{array}$ & Targeted food & $\begin{array}{l}\text { Enhanced } \\
\text { flavor }\end{array}$ & $\begin{array}{l}\text { Exposure } \\
\text { duration }\end{array}$ & $\begin{array}{c}\text { Impact on food } \\
\text { intake }^{5}\end{array}$ \\
\hline $\begin{array}{l}\text { Bellisle et } \\
\text { al.,1991 }\end{array}$ & 100 & $M=84$ yo & $\mathrm{NH}$ & WSD & $\begin{array}{l}2 \text { soups } \\
\text { Rice } \\
\text { Mashed potatoes }\end{array}$ & Umami taste & 3 meals & $\begin{array}{l}\lambda \text { for } 1 \text { soup } \\
\varnothing \\
\lambda\end{array}$ \\
\hline $\begin{array}{l}\text { Schiffman \& } \\
\text { Warwick, } \\
\text { 1993) }\end{array}$ & 39 & $M=85$ yo & $\mathrm{NH}$ & WSD & $\begin{array}{l}30 \text { various foods } \\
\text { (meat, vegetable, } \\
\text { breakfast food, } \\
\text { gravy...) }\end{array}$ & Flavor & 3 weeks & $\begin{array}{l}\boldsymbol{\lambda} \text { for } 3 \text { foods } \\
\varnothing \text { for others }\end{array}$ \\
\hline $\begin{array}{l}\text { De Jong et al., } \\
1996\end{array}$ & 25 & $>65$ yo & $\mathrm{NH}$ & WSD & $\begin{array}{l}\text { Strawberry jam } \\
\text { Strawberry yoghurt } \\
\text { Orange lemonade }\end{array}$ & Sweet taste & 5 days & $\begin{array}{l}\varnothing \\
\varnothing \\
\varnothing\end{array}$ \\
\hline $\begin{array}{l}\text { Griep et al., } \\
1997\end{array}$ & 20 & $>60$ yo & $\mathrm{NH}$ & WSD & $\begin{array}{l}\text { Tomato soup } \\
\text { Quorn } \\
\text { Yoghurt }\end{array}$ & Flavor & 1 meal & $\begin{array}{l}\varnothing \\
\varnothing \\
\pi\end{array}$ \\
\hline $\begin{array}{l}\text { Griep et al, } \\
2000, \\
\text { exp } 1 \text { yoghurt }\end{array}$ & 260 & $\begin{array}{l}33<40 y o \\
2340-60 \\
9861-80 \\
106>80 \text { yo }\end{array}$ & $\mathrm{CD}$ & BGD & Yoghurt & Flavor & 1 day & $\begin{array}{l}\text { No impact of } \\
\text { age on } \\
\text { preference and } \\
\text { intake for high } \\
\text { flavored sample }\end{array}$ \\
\hline $\begin{array}{l}\text { Griep et al, } \\
2000, \\
\exp 2 \text { Quorn }\end{array}$ & 120 & $\begin{array}{l}47<40 y o \\
1940-60 \\
3261-80 \\
22>80 \text { yo }\end{array}$ & $\mathrm{CD}$ & BGD & Quorn & Flavor & 1 day & $\begin{array}{l}\text { No impact of } \\
\text { age on } \\
\text { preference and } \\
\text { intake for high } \\
\text { flavored sample }\end{array}$ \\
\hline $\begin{array}{l}\text { Mathey et al., } \\
2001\end{array}$ & 71 & $M=84$ yo & NH & BGD & Protein dish & Flavor & 16 weeks & $\pi$ \\
\hline $\begin{array}{l}\text { Koskinen et } \\
\text { al., 2003b }\end{array}$ & 57 & $M=74$ yo & $\mathrm{CD}$ & WSD & Yosa & Flavor & 3 meals & $\varnothing$ \\
\hline $\begin{array}{l}\text { Essed et al., } \\
2007\end{array}$ & 97 & $M=85$ yo & $\mathrm{NH}$ & BGD & Protein dish & $\begin{array}{l}\text { Aroma Umami } \\
\text { taste }\end{array}$ & 16 weeks & $\varnothing$ \\
\hline $\begin{array}{l}\text { Pouyet et al., } \\
2015\end{array}$ & $\begin{array}{c}104 \\
\text { three } \\
\text { levels } \\
\text { of } \\
\text { MMS }\end{array}$ & $M=89$ yo & $\mathrm{NH}$ & WSD & Appetizer & Flavor & 1 meal & $\pi$ \\
\hline
\end{tabular}

${ }^{1}$ Sample size.

${ }^{2} M$ : mean age; yo: years old.

${ }^{3} \mathrm{CD}$ : community-dwelling elderly people; $\mathrm{NH}$ : nursing home residents. 
${ }^{4}$ WSD: within-subject design (all participant were subjected to the standard and the flavor-enhanced food); BGD: betweengroup design (a control group subjected to the standard food was compared to an experimental group subjected to the flavorenhanced food).

${ }_{5}^{5} \boldsymbol{\lambda}$ : flavor-enhancement led to a significant increase of food intake; $\varnothing$ : no significant effect of flavor-enhancement on food intake.

Some authors have investigated the impact of providing gravy or seasonings on food intake in institutionalized elderly people, in an attempt to provide a more appropriate and personalised experience of sensory enhancement. Appleton (2009) observed that adding sauce to the protein part of a meal increased energy intake, but the increase in energy consumed resulted from the additional consumption of energy from the sauce rather than an increase in intake of meat/fish or vegetable consumption. Divert, Laghmaoui, Crema, Issanchou, Van Wymelbeke and SulmontRossé (2015) provided nursing home residents with several seasonings such as butter, tomato sauce, lemon, parsley, mayonnaise, and so on. These seasoning were presented in bowls placed in the middle of the table and residents were free to help themselves whenever they wished during the meal. Results showed a positive impact of seasoning on meal enjoyment and food intake. Finally, in a recent study, we used a methodology following the reverse engineering principle to improve the sensory quality of food according to the sensory expectations of elderly people (Sulmont-Rossé, Symoneaux, Feyen \& Maître, in press). This strategy consisted of $i$. exploring food expectations of elderly people through qualitative survey, $i i$. developing food prototypes on the basis of the qualitative results, and iii. assessing the prototypes by running hedonic tests with elderly people. First results indicate that prototypes developed using this 'reverse engineering' approach and integrating elderly feedback received higher hedonic ratings than commercial products. These prototypes with improved overall sensory characteristics (texture, taste and aroma) were preferred to prototypes that were enhanced for flavour alone (Sulmont-Rossé et al., in press). This suggests a multidimensional approach may be more successful when developing food for the elderly population (see also Forde \& Delahunty, 2004; Kremer, Holthuysen \& Boesveldt, 2014). 


\section{(4.3) Future perspectives for food development for older populations}

Many studies have highlighted a decrease of odour and taste perception due to ageing though large inter-individual variability has been seen in changes to chemosensory perception and the impact this has on food-related behaviours within this heterogeneous population. Most studies have explored olfactory orthonasal perception, rather than retronasal perception and several authors have suggested orthonasal performance poorly predicts the retronasal experience, especially when dealing with complex food (Duffy, Backstrand \& Ferris, 1995; Duffy, Cain \& Ferris, 1999; Koskinen, Vento, Malmberg, \& Tuorila, 2004; Koskinen \& Tuorila, 2005). Assuming that retro-nasal perception is more related to eating pleasure and eating behavior than orthonasal perception, it is important to develop retro-nasal olfactory tests for this population. In parallel, many of the studies have explored the impact of flavour enhancement on food intake in older people and provided mixed results. Recent findings demonstrate that it is more effective to improve the sensory quality of foods dedicated to older consumers taking into account their hedonic expectations. This suggests the need for a more holistic approach to flavour enhancement and product development, considering all aspects of the sensory experience of food (aroma and taste, but also texture, vision) rather than only one (Forde \& Delahunty, 2004; Kremer et al., 2014; Sulmont-Rossé et al., in press). In the case of smell loss, it could be assumed that it is likely better to have more pleasure elicited by the remaining senses, than to try to replace losses to the sense of smell through aroma addition within a food.

To date, the studies that have investigated the impact of age on chemosensory perception and eating behaviour have mainly included "healthy" elderly people (see for instance Mojet et al., 2003; Koskinen \& Tuorila, 2005), or at least people not suffering from neurodegenerative disease that prevent them from completing chemosensory tests and/or an acute pathological event such as a cancer (see for instance Sulmont-Rossé et al., 2015). However, ageing is associated with an increase in the prevalence of many diseases and it is important to how a poorhealth status might strengthen the burden of physiological ageing on chemosensory perception to impact food-related behaviour further.

\section{(5.0) Chemosensory perception in poor-health and disease}

As described above, chemosensory perception plays a crucial role in food choices and intake, and thus in maintaining a healthy nutritional status, over the entire life course. These sensory 
aspects of a food are not only drivers of preferences and aversions, but are also important for steering appetite, signalling nutrient content and satiety processes (Boesveldt and De Graaf, 2017, McCrickerd and Forde, 2016). However, prominent illness and related concomitant treatment, including neurodegenerative diseases, cancer and chemotherapy, may lead to changes in smell or taste function and thereby alter flavour perception and eating behaviour.

\section{(5.1) Neurodegenerative disease}

\section{(5.1.1) Alzheimer's disease}

Alzheimer's disease (AD) has been coined one of the grand challenges of the current century, with over 35 million people worldwide suffering from dementia (ADI, 2012). AD develops gradually over many years, and the first brain changes (i.e. amyloid deposition and tau pathology) can be detected up to 20 years prior to onset of the clinical syndrome of dementia, characterised by memory impairment and global cognitive decline (Bateman et al., 2012). Loss of smell (olfactory dysfunction) is one of the earliest features of AD (Lafaille-Magnan et al., 2017, Roberts et al., 2016) and can be predictive for cognitive decline, as well as for the conversion of mild cognitive impairment (MCI) to dementia (Olofsson et al., 2016, Roberts et al., 2016, Stanciu et al., 2015). In addition to this, taste impairments are reported in AD, as well as in MCI (Broggio et al., 2001, Sakai et al., 2016, Steinbach et al., 2010). Though these chemosensory changes have not been explicitly linked to nutrition behaviour in AD, involuntary weight loss often occurs and malnutrition is a frequently reported phenomenon in this disease (ADI, 2014, Stewart et al., 2005). Weight loss may result from a combination of causes, including chemosensory loss, reduced appetite, and, in the more advanced stages of the illness, the disruption of eating behaviour by cognitive and behavioural problems, leading to reduced intake, altered uptake of nutrients and changes in metabolism.

\section{(5.1.2) Parkinson's disease}

Parkinson's disease (PD) is the second most common neurodegenerative disorder, a movement disorder that is characterized by motor symptoms, such as bradykinesia (slowing of movement), tremor, rigidity and postural instability. Olfactory deficits in PD were first empirically documented in 1975 by Ansari and Johnson (Ansari and Johnson, 1975), and have become an established feature of the disease over the ensuing years (Rahayel et al., 2012). The prevalence 
of olfactory loss in PD patients ranges between 50-90\% (Haehner et al., 2009). Interestingly, olfactory dysfunction is often already present in early stages of the disease, as confirmed by the neuropathological staging by Braak (Braak et al., 2003), and can possibly provide a first sign of incipient PD (Ponsen et al., 2004) as well as predict cognitive decline. The incidence, extent and pathophysiology of taste (dys)function in PD, is less clear, though appears to be limited (for review, see Cecchini et al., 2015). PD is associated with an increased risk of malnutrition and a lower BMI relative to healthy controls (Sheard et al., 2011, Chen et al., 2003, van der Marck et al., 2012, Mun et al., 2016). Although a recent pilot study suggested that olfactory, but not gustatory function, is associated with BMI in patients (Roos et al. submitted), the exact contribution of smell or taste loss to nutritional status is unclear. Pharmaceutical treatment of PD can also lead to complications for perception, metabolism and reward. For instance the drug levodopa is used to treat PD and its dosage could be related to the risk of malnutrition, because of the higher energy metabolism in rigidity or dyskinesia (Barichella et al., 2013, Barichella et al., 2009). In addition, levodopa acts on the dopaminergic reward system, which makes the patients susceptible to aberrant behaviours and can manifest as an increased tendency towards gambling, alcohol, sex, and food intake.

Similar to AD, the underlying causes for weight loss or malnutrition may be multifactorial, and not solely reflect chemosensory alterations. It is crucial to try and disentangle these different causes in order to come up with specific strategies to counteract malnutrition in these patients. Moreover, the preclinical stages of $\mathrm{PD}$ as well as $\mathrm{AD}$, in which olfactory loss is already prominent, may offer a unique window for intervention to maintain nutritional status and potentially even slow down disease progression.

\section{(5.2) Cancer and chemotherapy}

Cancer is one of the leading causes of morbidity and mortality worldwide. Earlier detection and developments in cancer treatment have resulted in an increase in the cancer survival rates in the past decades which are still growing. As a result, the long-term side effects of cancer treatment are becoming more and more important. Changes in taste and smell perception are frequently reported side-effects, with the prevalence ranging from $45 \%$ to $85 \%$ for self-reported taste changes and 5\% to $60 \%$ for smell changes (Gamper et al., 2012b). These chemosensory 
alterations have been described as an absence of taste or smell, reduced or increased sensitivity, distortion of taste or smell, phantom tastes or odours and metallic sensations, and many cancer patients undergoing chemotherapy report that their food no longer tastes the same. Clearly, this can have a substantial impact on the daily life of cancer patients by reducing food enjoyment, nutritional intake and quality of life (de Vries et al., 2016, Boltong and Keast, 2012, Gamper et al., 2012a, Hutton et al., 2007, Zabernigg et al., 2010). Typically, taste and smell changes can start during the first infusion of chemotherapy (Gamper et al., 2012b), and longitudinal studies show that these changes are mostly transient and recover after chemotherapy (Steinbach et al., 2009, de Vries et al., 2018). Though sensory cues play an important role in eating behaviour (Boesveldt and De Graaf, 2017), chemosensory perception is not always directly linked to nutritional status (Toussaint et al., 2015). In breast cancer patients however, chemosensory changes have been shown to be associated with changes in food preferences (de Vries et al., 2018), and can thereby contribute to changed dietary intake (de Vries et al., 2017) and nutritional status or weight/body composition changes.

Overall, a poorer nutritional status may have adverse effects on disease progression and treatment outcome, and it is thus paramount to monitor chemosensory changes over the course of illness or medical treatment.

\section{(5.3) Combatting changes in chemosensory perception during poor health and disease}

As alluded to above, smell and/or taste changes can be prominent features of disease or occur as side-effects from treatment. Though such alterations are sometimes neglected or disregarded as being of minor importance, they can actually have a severe impact on quality of life and nutritional status, or even be used as a biomarker to identify patients at risk for the development of neurodegenerative disorders. Prevention of cognitive decline through early-stage dietary intervention is an attractive approach - especially since curative therapy for these neurodegenerative diseases is not available now or in the near future - but should be based on further evidence to formulate specific dietary guidelines or develop targeted nutritional products for patients at risk. In addition, nutritional strategies should not overlook the importance of sensory characteristics of a product, and take into account smell and taste as part of the flavour percept, which is vital for food enjoyment and dietary compliance. For cancer patients, given the 
heterogeneity of the disease and treatment options, it is vital to obtain better insight into the underlying mechanisms (e.g. by animal or cell-based research) and varying effects on chemosensory changes and nutrition to develop potential strategies to counteract these changes. Managing patient expectations by informing them of the transient nature of these changes can be taken as an initial step.

\section{(6.0) Conclusions}

The acquisition of food preferences in infancy and early childhood appears to be primarily driven by mere exposure and learning to accept new tastes and smells, yet it remains unclear which elements of these early-life experiences have a lasting impact on food preference and intake behaviours into adulthood. There are significant gaps in our understanding of the links between early life experiences with food and the development of eating behaviours. More broadly, there are opportunities to shape long term dietary patterns through strategies that target the introduction of appropriate sensory experiences at different stages during development (i.e. in utero, during the transition to a solid food diet and during early childhood). In adulthood the sensory systems play an important functional role in how we navigate our food environment. Food odour, taste and texture have traditionally been considered in the context of their impact on food likes and dislikes, but an increasing body of evidence highlights the importance of the senses in guiding calorie selection, stimulating appetite and moderating energy intake. For healthy children and adults, modifying food texture may prove an effective strategy to optimise both sensory appeal and eating behaviour associated with consumption.

As we age, many older consumers experience significant decreases in sensory acuity, texture perception and chewing efficiency that can impact perception and enjoyment of foods. Compensating for sensory loss through flavour enhancement has proved challenging, primarily due to the heterogeneity of sensory perception in this population and the increasingly individual nature of food preferences and nutritional needs later in life. There remains no consensus on the best approach to be applied across products or populations, but the use of multiple sensory enhancements across texture, aroma and taste in real-foods seems to hold most promise for enhancing food intake. Many older consumers are at a higher risk of chronic illnesses and neurodegenerative conditions and this can further damage an already compromised sensory 
system though both the disease pathology and their clinical treatment. A loss of appetite and significant weight loss frequently accompanies the development of these conditions, and there is a need to improve nutritional and sensory strategies to promote food acceptance and intake and improve treatment outcomes among vulnerable populations.

The current paper provides an overview of the changing role of the senses in food choice and appetite control changes across the lifespan. An appreciation of the importance of sensory factors in the development of food intake behaviours and the aetiology of non-communicable chronic diseases, coupled with an understanding of their potential to moderate food choice and intake, will create opportunities to apply sensory approaches to improve dietary behaviours for health. 


\section{(7.0) Acknowledgements.}

CSR and IM acknowledge the AUPALESENS project - Improving the pleasure of elderly people for better ageing and to fight against malnutrition - funded by the French National Research Agency (ANR-09-ALIA-011-02). It was also supported by grants from the Regional Council of Burgundy France (PARI Agral 1) and the European Funding for Regional Economic Development (FEDER).

CGF and KMc acknowledge the Biomedical Science Institute Strategic Positioning Fund Grant (G00067; BMSI/13-80048C-SICS: (Sensory Nutritional Science) and the Nestec-Epigen Research Centre Collaboration fund (G00067; BMSI/15-300004-SICS).

NB acknowledges the Academic Professional Development Committee at St. Catherine University.

\section{Conflict of Interest;}

The authors declare no conflicts of interest.

The research was presented as part of the Workshop "Chemosensory influences on food choice and intake" at the $12^{\text {th }}$ Pangborn Sensory Science Symposium, in Providence, Rhode Island. 


\section{References}

1. Almiron-Roig, E., Palla, L., Guest, K., Ricchiuti, C., Vint, N., Jebb, S. A., \& Drewnowski, A. (2013). Factors that determine energy compensation: a systematic review of preload studies. Nutrition Reviews, 71(7), 458-473. doi:10.1111/nure.12048

2. Alzheimer's Disease International (ADI) and W.H.O.(2012)., Dementia: a public health priority, 2012 ISBN: 97892415644582012.

3. Alzheimer's Disease International (ADI), London. Feb 2014 Eds Martin Prince, Emiliano Albanese, Maëlenn Guerchet, Matthew Prina, Nutrition and dementia: a review of available research, M. Prince, et al., Editors. 2014: London.

4. Amoore, J. E. (1986). Effects of Chemical Exposure on Olfaction in Humans. In Toxicology of the Nasal Passages. In C. Barrow, Toxicology of the Nasal Passages. Washington, USA: Hemisphere Publishing Corporation.

5. Ansari, K.A. and A. Johnson, Olfactory Function in Patients with Parkinsons-Disease. Journal of Chronic Diseases, 1975. 28(9): p. 493-497.

6. Appleton, K. M. (2009). Increases in energy, protein and fat intake following the addition of sauce to an older person's meal. Appetite, 52, 161-165.

7. Barichella, M., E. Cereda, and G. Pezzoli, Major nutritional issues in the management of Parkinson's disease. Mov Disord, 2009. 24(13): p. 1881-92.

8. Barichella, M., et al., Nutritional risk and gastrointestinal dysautonomia symptoms in Parkinson's disease outpatients hospitalised on a scheduled basis. Br J Nutr, 2013. 110(2): p. 347-53.

9. Bateman, R.J., et al., Clinical and Biomarker Changes in Dominantly Inherited Alzheimer's Disease. New England Journal of Medicine, 2012. 367(9): p. 795-804.

10. Beauchamp, G. K., \& Cowart, B. J. (1990). Preference for high salt concentrations among children. Developmental Psychology, 26(4), 539.

11. Beauchamp, G. K., \& Moran, M. (1982). Dietary experience and sweet taste preference in human infants. Appetite, 3(2), 139-152.

12. Beauchamp, G. K., \& Moran, M. (1984). Acceptance of sweet and salty tastes in 2-yearold children. Appetite, 5(4), 291-305.

13. Beauchamp, G. K., Cowart, B. J., \& Moran, M. (1986). Developmental changes in salt acceptability in human infants. Developmental Psychobiology, 19(1), 17-25. 
14. Bellisle, F., Monneuse, M. O., Chabert, M., Larue-Achagiotis, C., Lanteaume, M. T., \& Louis-Sylvestre, J. (1991). Monosodium glutamate as a palatability enhancer in the European diet. Physiology \& Behavior, 49, 869-873.

15. Birch, L. L., \& Fisher, J. O. (1998). Development of eating behaviors among children and adolescents. Pediatrics, 101(Supplement 2), 539-549.

16. Blundell, J. E., de Graaf, C., Hulshof, T., Jebb, S., Livingstone, B. M., Lluch, A., . . . Westerterp, M. (2010). Appetite control: methodological aspects of the evaluation of foods. Obesity Reviews, 11(3), 251-270.

17. Bobowski, N. \& Mennella, J. A. (2017). Personal Variation in Preference for Sweetness: Effects of Age and Obesity. Childhood Obesity. doi: 10.1089/chi.2017.0023.

18. Boesveldt, S. and C. De Graaf, The differential role of smell and taste for eating behavior. Perception, 2017. 46: p. 307-319.

19. Bolhuis, D. P., Forde, C. G., Cheng, Y., Xu, H., Martin, N., \& de Graaf, C. (2014). Slow Food: Sustained Impact of Harder Foods on the Reduction in Energy Intake over the Course of the Day. Plos One, 9(4), e93370. doi:10.1371/journal.pone.0093370.

20. Bolhuis, D. P., Lakemond, C. M. M., de Wijk, R. A., Luning, P. A., \& de Graaf, C. (2010). Effect of Salt Intensity on Ad Libitum Intake of Tomato Soup Similar in Palatability and on Salt Preference after Consumption. Chemical Senses, 35(9), 789-799. doi:10.1093/chemse/bjq077.

21. Bolhuis, D. P., Lakemond, C. M. M., de Wijk, R. A., Luning, P. A., \& de Graaf, C. (2011). Both Longer Oral Sensory Exposure to and Higher Intensity of Saltiness Decrease Ad Libitum Food Intake in Healthy Normal-Weight Men. Journal of Nutrition, 141(12), 2242-2248. doi:10.3945/jn.111.143867.

22. Bolhuis, D. P., Lakemond, C. M. M., de Wijk, R. A., Luning, P. A., \& de Graaf, C. (2012). Effect of salt intensity in soup on ad libitum intake and on subsequent food choice. Appetite, 58(1), 48-55. doi:http://dx.doi.org/10.1016/j.appet.2011.09.001.

23. Boltong, A. and R. Keast, The influence of chemotherapy on taste perception and food hedonics: A systematic review. Cancer Treatment Reviews, 2012. 38(2): p. 152-163.

24. Braak, H., et al., Staging of brain pathology related to sporadic Parkinson's disease. Neurobiology of Aging, 2003. 24(2): p. 197-211. 
25. Broggio, E., et al., Taste impairment in Alzheimer's disease. Revue Neurologique, 2001. 157(4): p. 409-413.

26. Brunstrom, J. M. (2014). Mind over platter: pre-meal planning and the control of meal size in humans. Int J Obes, 38(S1), S9-S12. doi:10.1038/ijo.2014.83.

27. Bufe, B., Breslin, P. A., Kuhn, C., Reed, D. R., Tharp, C. D., Slack, J. P., ... \& Meyerhof, W. (2005). The molecular basis of individual differences in phenylthiocarbamide and propylthiouracil bitterness perception. Current Biology, 15(4), 322-327.

28. Burnier, D., Dubois, L., \& Girard, M. (2011). Exclusive breastfeeding duration and later intake of vegetables in preschool children. European Journal of Clinical Nutrition, 65(2), 196.

29. Cain, W. S., \& Murphy, C. (1987). Influence of aging on recognition memory for odors and graphic stimuli. Annals of the New-York Academy of Sciences, 510, 212-215.

30. Cecchini, M.P., et al., Taste in Parkinson's disease. Journal of Neurology, 2015. 262(4): p. $806-813$.

31. Chen, H., et al., Weight loss in Parkinson's disease. Ann Neurol, 2003. 53(5): p. 676-9.

32. Coelho, J. S., Polivy, J., Peter Herman, C., \& Pliner, P. (2009). Wake up and smell the cookies. Effects of olfactory food-cue exposure in restrained and unrestrained eaters. Appetite, 52(2), 517-520. doi:http://dx.doi.org/10.1016/j.appet.2008.10.008

33. Cooke, L. (2007). The importance of exposure for healthy eating in childhood: a review. Journal of human nutrition and dietetics, 20(4), 294-301.

34. Cooke, L. J., Wardle, J., Gibson, E. L., Sapochnik, M., Sheiham, A., \& Lawson, M. (2004). Demographic, familial and trait predictors of fruit and vegetable consumption by pre-school children. Public health nutrition, 7(2), 295-302.

35. Corwin, J., Loury, M., \& Gilbert, A. N. (1995). Workplace, age, and sex as mediators of olfactory function: data from the National Geographic Smell Survey. The Journals of Gerontology. Series B, Psychological Sciences and Social Sciences, 50(4), 179-186.

36. De Graaf, C., \& Zandstra, E. H. (1999). Sweetness intensity and pleasantness in children, adolescents, and adults. Physiology \& behavior, 67(4), 513-520.

37. De Jong, N., De Graaf, C., \& Van Staveren, W. (1996). Effect of sucrose in breakfast items on pleasantness and food intake in the elderly. Physiology \& Behavior, 60(6), 1453-1462. 
38. de Vries, Y.C., et al., Altered food preferences and chemosensory perception during chemotherapy in breast cancer patients: A longitudinal comparison with healthy controls Original Food Quality and Preference, 2018. 63: p. 135-143.

39. de Vries, Y.C., et al., Differences in dietary intake during chemotherapy in breast cancer patients compared to women without cancer. Supportive Care in Cancer, 2017. 25(8): p. 2581-2591.

40. de Vries, Y.C., et al., The impact of chemosensory and food-related changes in patients with advanced oesophagogastric cancer treated with capecitabine and oxaliplatin: a qualitative study. Supportive Care in Cancer, 2016. 24(7): p. 3119-3126.

41. de Wijk, R. A., Polet, I. A., Boek, W., Coenraad, S., \& Bult, J. H. F. (2012). Food aroma affects bite size. Flavour, 1(1), 1-6.

42. Desor, J. A., Maller, O., \& Turner, R. E. (1973). Taste in acceptance of sugars by human infants. Journal of Comparative and Physiological Psychology, 84(3), 496.

43. Dhillon, J., Running, C. A., Tucker, R. M., \& Mattes, R. D. (2016). Effects of food form on appetite and energy balance. Food Quality and Preference. doi:http://dx.doi.org/10.1016/j.foodqual.2015.03.009

44. Divert, C., Laghmaoui, R., Crema, C., Issanchou, S., Van Wymelbeke, V., \& SulmontRosse, C. (2015). Improving meal context in nursing homes. Impact of four strategies on food intake and meal pleasure. Appetite, 84, 139-147.

45. Doty, R. L. (1991). Olfactory dysfunction in neurodegenerative disorders. In T. V. Getchell, R. L. Doty, L. M. Bartoshuk \& J. B. Snow, Smell and Taste in Health and Disease. New York: Raven Press.

46. Doty, R. L., \& Bromley, S. M. (2004). Effects of drugs on olfaction and taste. Otolaryngologic Clinics of North America, 37(6), 1229-1254.

47. Doty, R. L., Shaman, P., Appelbaum, S. L., Giberson, R., Siksorski, L., \& Rosenberg, L. (1984). Smell identification: Changes with age. Science, 226(4681), 1441-1443.

48. Drewnowski, A., \& Rehm, C. D. (2014). Consumption of added sugars among US children and adults by food purchase location and food source. The American Journal of Clinical Nutrition, 100(3), 901-907.

49. Drewnowski, A., \& Specter, S. E. (2004). Poverty and obesity: the role of energy density and energy costs. The American Journal of Clinical Nutrition, 79(1), 6-16. 
50. Duffy VB. Multi-level interventions to improve vegetable consumption in children. (2013). Poster presented at AAAS Annual Meeting, Boston, MA.

51. Duffy, V. B., Backstrand, J. R., \& Ferris, A. M. (1995). Olfactory dysfunction and related nutritional risk in free-living elderly women. Journal of the American Dietetic Association, 95(8), 879-884.

52. Duffy, V. B., Cain, W. S., \& Ferris, A. M. (1999). Measurement of sensitivity to olfactory flavour: Application in a study of aging and dentures. Chemical Senses, 24(6), 671-677.

53. Essed, N. H., van Staveren, W. A., Kok, F. J., \& de Graaf, C. (2007). No effect of 16 weeks flavour enhancement on dietary intake and nutritional status of nursing home elderly. Appetite, 48(1), 29-36.

54. Ferriday, D., \& Brunstrom, J. M. (2008). How does food-cue exposure lead to larger meal sizes? British Journal of Nutrition, 100(6), 1325-1332. doi:10.1017/s0007114508978296.

55. Ferriday, D., \& Brunstrom, J. M. (2011). 'I just can't help myself': effects of food-cue exposure in overweight and lean individuals. International Journal of Obesity, 35(1), 142-149.

56. Fogel, A., Goh, A.T., Edelson, L., Sadananthan, S., Velan, S., Michael, N., Tint, M.T., Fortier, M.V., Chan, M.C., Chong, C.Y., Tan, K.H., Yap, F., Shek, L. Meaney, M., Broekman, B., Lee, Y.S., Godfrey, K., Chong, M.F.F. and Forde, C.G. (2017a). A description of the 'obesogenic' eating style that promotes greater adiposity in pre-school children; Results from the GUSTO cohort. Physiology and Behaviour doi: Volume 176, 107-116 10.1016/j.physbeh.2017.02.013.

57. Fogel, A., Goh, A.T., Edelson, L., Sadananthan, S., Velan, S., Michael, N., Tint, M.T., Fortier, M.V., Chan, M.C., Chong, C.Y., Tan, K.H., Yap, F., Shek, L. Meaney, M., Broekman, B., Lee, Y.S., Godfrey, K., Chong, M.F.F. \& Forde, C.G. (2017b). Faster eating rates are associated with higher ad libitum energy intakes, higher BMI and greater adiposity among 4.5 year old children; Results from the GUSTO cohort. British Journal of Nutrition Volume 117, Issue 7 pp. 1042-1051.DOI:10.1017/S0007114517000848. 
58. Forde, C. G., \& Delahunty, C. M. (2004). Understanding the role cross-modal sensory interactions play in food acceptability in younger and older consumers. Food Quality and Preference, 15(7-8), 715-727.

59. Forde, C. G., Leong, C., Chia-Ming, E., \& McCrickerd, K. (2017). Fast or slow-foods? Describing natural variations in oral processing characteristics across a wide range of Asian foods. Food and Function, 8(2), 595-606. doi:10.1039/C6FO01286H.

60. Forde, C. G., Lim, C. M. H., Leong, C., Chia, E. M., \& McCrickerd, K. (2016). Food texture and energy density interact to influence the microstructure of eating and energy intake. Paper presented at the Society for the Study of Ingestive Behaviour Annual Meeting, Porto, Portugal.

61. Forde, C. G., van Kuijk, N., Thaler, T., de Graaf, C., \& Martin, N. (2013a). Oral processing characteristics of solid savoury meal components and relationship with food composition, sensory attributes and expected satiation. Appetite, 60(0), 208-219. doi:http://dx.doi.org/10.1016/j.appet.2012.09.015

62. Forde, C. G., van Kuijk, N., Thaler, T., de Graaf, C., \& Martin, N. (2013b). Texture and savoury taste influences on food intake in a realistic hot lunch time meal. Appetite, 60, 180-186.

63. Fusari, A., \& Ballesteros, S. (2008). Identification of odors of edible and nonedible stimuli as affected by age and gender. Behavior Research Methods, 40(3), 752-759.

64. Gaillet, M., Sulmont-Rossé, C., Issanchou, S., Chabanet, C., \& Chambaron, S. (2013). Priming effects of an olfactory food cue on subsequent food-related behaviour. Food $\begin{array}{llll}\text { Quality and } & \text { 274-281. }\end{array}$ doi:http://dx.doi.org/10.1016/j.foodqual.2013.06.008.

65. Gaillet-Torrent, M., Sulmont-Rossé, C., Issanchou, S., Chabanet, C., \& Chambaron, S. (2014). Impact of a non-attentively perceived odour on subsequent food choices. Appetite, 76(0), 17-22. doi:http://dx.doi.org/10.1016/j.appet.2014.01.009.

66. Gamper, E.M., et al., Coming to Your Senses: Detecting Taste and Smell Alterations in Chemotherapy Patients. A Systematic Review. Journal of Pain and Symptom Management, 2012. 44(6): p. 880-895. 
67. Gamper, E.M., et al., Taste alterations in breast and gynaecological cancer patients receiving chemotherapy: Prevalence, course of severity, and quality of life correlates. Acta Oncologica, 2012. 51(4): p. 490-496.

68. Glendinning, J. I. (1994). Is the bitter rejection response always adaptive? Physiology \& behavior, 56(6), 1217-1227.

69. Griep, M. I., Mets, T. F., \& Massart, D. L. (1997). Different effects of flavour amplification of nutrient dense foods on preference and consumption in young and elderly subjects. Food Quality and Preference, 8(2), 151-156.

70. Griep, M. I., Mets, T. F., \& Massart, D. L. (2000). Effects of flavour amplification of Quorn ${ }^{\circledR}$ and yoghurt on food preference and consumption in relation to age, BMI and odour perception. British Journal of Nutrition, 83(02), 105-113.

71. Haehner, A., et al., Prevalence of smell loss in Parkinson's disease--a multicenter study. Parkinsonism Relat Disord, 2009. 15(7): p. 490-4.

72. Henkin, R. I., Levy, L. M., \& Fordyce, A. (2013). Taste and smell function in chronic disease: A review of clinical and biochemical evaluations of taste and smell dysfunction in over 5000 patients at The Taste and Smell Clinic in Washington, DC. American Journal of Otolaryngology, 34(5), 477-489.

73. Hogenkamp, P. S., Stafleu, A., Mars, M., Brunstrom, J. M., \& de Graaf, C. (2011). Texture, not flavour, determines expected satiation of dairy products. Appetite, 57(3), 635-641.

74. Hutton, J.L., Baracos, V.E. and W.V. Wismer, Chemosensory dysfunction is a primary factor in the evolution of declining nutritional status and quality of life in patients with advanced cancer. Journal of Pain and Symptom Management, 2007. 33(2): p. 156-165.

75. Imoscopi, A., Inelmen, E. M., Sergi, G., Miotto, F., \& Manzato, E. (2012). Taste loss in the elderly: epidemiology, causes and consequences. Aging Clinical and Experimental Research, 24(6), 570-579.

76. Institute of Medicine (2010). Strategies to reduce sodium intake in the United States. In J. E. Henney, C. L. Taylor, \& C. S. Boon (Eds.). Washington, DC: The National Academies Press. 
77. Jackson, S. L., King, S. M., Zhao, L., \& Cogswell, M. E. (2016). Prevalence of excess sodium intake in the United States-NHANES, 2009-2012. MMWR Morb Mortal Wkly Rep, 64(52), 1393-7.

78. Kajiura, H., Cowart, B. J., \& Beauchamp, G. K. (1992). Early developmental change in bitter taste responses in human infants. Developmental Psychobiology, 25(5), 375-386.

79. Kaneda, H., Maeshima, K., Kobayakawa, T., Ayabe-Kanamura, S., \& Saito, S. (1998). Comparison between young and elderly people in quality discrimination and identification of mixed odors and tastes. Chemical Senses, 23(2), 228.

80. Karl, J. P., Young, A. J., Rood, J. C., \& Montain, S. J. (2013). Independent and Combined Effects of Eating Rate and Energy Density on Energy Intake, Appetite, and Gut Hormones. Obesity, 21(3), E244-E252. doi:10.1002/oby.20075

81. Kim, S. A., Moore, L. V., Galuska, D., Wright, A. P., Harris, D., Grummer-Strawn, L. M., Merlo, C.L., Nihiser, A.J. \& Rhodes, D.G. (2014. MMWR Morb Mortal Wkly Rep, 63, (31), 671-676.

82. Koskinen, S., \& Tuorila, H. (2005). Performance on an odor detection and identification test as a predictor of ortho- and retronasal odor intensity ratings in the young and elderly. Food Quality and Preference, 16(5), 383-392.

83. Koskinen, S., Kälviäinen, N., \& Tuorila, H. (2003). Flavor enhancement as a tool for increasing pleasantness and intake of a snack product among the elderly. Appetite, 41(1), 87-96.

84. Koskinen, S., Kälviäinen, N., \& Tuorila, H. (2003). Perception of chemosensory stimuli and related responses to flavored yogurts in the young and elderly. Food Quality and Preference, 14(8), 623-635.

85. Koskinen, S., Vento, S., Malmberg, H., \& Tuorila, H. (2004). Correspondence between three olfactory tests and suprathreshold odor intensity ratings. Acta Oto-Laryngologica, 124(9), 1072-1077.

86. Kremer, S., Holthuysen, N., \& Boesveldt, S. (2014). The influence of olfactory impairment in vital, independently living older persons on their eating behaviour and food liking. Food Quality and Preference, 38, 30-39.

87. Lafaille-Magnan, M.E., Poirier, J., Etienne, P., Tremblay-Mercier, J., Frenette, J., RosaNeto, P., Breitner, J.C.S., \& For the PREVENT-AD Research Group. Odor identification 
as a biomarker of preclinical AD in older adults at risk. Neurology, 2017. 89(4): p. 327335.

88. Larsson, M. (1996). Odor and source remembering in adulthood and aging. Kongl Karolinska Medico Chirurgiska Institutet, Stockholm.

89. Larsson, M., \& Bäckman, L. (1993). Semantic activation and episodic odor recognition in young and older adults. Psychology and Aging, 8(4), 582-588.

90. Laureati, M., Pagliarini, E., \& Calcinoni, O. (2008). Does the enhancement of chemosensory stimuli improve the enjoyment of food in institutionalized elderly people? Journal of Sensory Studies, 23(2), 234-250.

91. Lucas, F., \& Bellisle, F. (1987). The measurement of food preferences in humans: Do taste-and-spit tests predict consumption? Physiology \& Behavior, 39(6), 739-743. doi:http://dx.doi.org/10.1016/0031-9384(87)90259-9.

92. Mackay-Sim, A., Johnston, A. N. B., Owen, C., \& Burne, T. H. J. (2006). Olfactory ability in the healthy population: Reassessing presbyosmia. Chemical Senses, 31(8), 763 771.

93. Maone, T. R., Mattes, R. D., Bernbaum, J. C., \& Beauchamp, G. K. (1990). A new method for delivering a taste without fluids to preterm and term infants. Developmental Psychobiology, 23(2), 179-191.

94. Mathey, M. F., Siebelink, E., de Graaf, C., \& van Staveren, W. A. (2001). Flavor enhancement of food improves dietary intake and nutritional status of elderly nursing home residents. The Journals of Gerontology. Series A, Biological Sciences and Medical Sciences, 56(4), M200-M205.

95. McCrickerd, K., \& Forde, C. G. (2016). Sensory influences on food intake control: moving beyond palatability. Obesity Reviews, 17(1), 18-29. doi:10.1111/obr.12340.

96. McCrickerd, K., Chambers, L., Brunstrom, J. M., \& Yeomans, M. R. (2012). Subtle changes in the flavour and texture of a drink enhance expectations of satiety. Flavour, 1(20), 1-11.

97. McCrickerd, K., Lensing, N., \& Yeomans, M. R. (2015). The impact of food and beverage characteristics on expectations of satiation, satiety and thirst. Food Quality and Preference, 44(0), 130-138. doi:http://dx.doi.org/10.1016/j.foodqual.2015.04.003. 
98. McCrickerd, K., Lim, C. M. H., Leong, C., Chia, E. M., \& Forde, C. G. (2017). TextureBased Differences in Eating Rate Reduce the Impact of Increased Energy Density and Large Portions on Meal Size in Adults. Journal of Nutrition, 147(6), 1208-1217. doi:10.3945/jn.116.244251.

99. Mennella, J. A. (2014). Ontogeny of taste preferences: basic biology and implications for health. The American Journal of Clinical Nutrition, 99(3), 704S-711S.

100. Mennella, J. A., \& Bobowski, N. (2015). The sweetness and bitterness of childhood: Insights from basic research on taste preferences. Physiology \& Behavior, $152,502-507$.

101. Mennella, J. A., Colquhoun, T. A., Bobowski, N., Olmstead, J. W., Bartoshuk, L., \& Clark, D. (2017). Farm to Sensory Lab: Taste of Blueberry Fruit by Children and Adults. Journal of Food Science, 82(7):1713-1719.

102. Mennella, J. A., Finkbeiner, S., Lipchock, S. V., Hwang, L. D., \& Reed, D. R. (2014). Preferences for salty and sweet tastes are elevated and related to each other during childhood. PLoS One, 9(3), e92201.

103. Mennella, J. A., Jagnow, C. P., \& Beauchamp, G. K. (2001). Prenatal and postnatal flavor learning by human infants. Pediatrics, 107(6), e88-e88.

104. Mennella, J. A., Pepino, M. Y., Duke, F. F., \& Reed, D. R. (2010). Age modifies the genotype-phenotype relationship for the bitter receptor TAS2R38. BMC Genetics, $11(1), 60$.

105. Methven, L., Allen, V. J., Withers, C. A., \& Gosney, M. A. (2012). Ageing and taste. Proceedings of the Nutrition Society, 71(4), 556-565.

106. Mingioni, M., Mehinagic, E., Siucinska, K., Konopacka, D., Artigas, G., Symoneaux, R., \& Maitre, I. (2017). Sweet and sour discrimination abilities of elderly people compared to those of young adults in apple puree. Food Quality and Preference, 59, 59-67.

107. Mojet, J., Heidema, J., \& Christ-Hazelhof, E. (2003). Taste perception with age: Generic or specific losses in supra-threshold intensities of five taste qualities? Chemical Senses, 28(5), 397-413. 
108. Mun, J.K., et al., Weight Change Is a Characteristic Non-Motor Symptom in Drug-Naive Parkinson's Disease Patients with Non-Tremor Dominant Subtype: A Nation-Wide Observational Study. PLoS One, 2016. 11(9): p. e0162254.

109. Murphy, C., Cain, W. S., Gilmore, M. M., \& Skinner, R. B. (1991). Sensory and semantic factors for recognition memory for odors and graphic stimuli: elderly versus young persons. American Journal of Psychology, 104(2), 161-192.

110. Murphy, C., Schuberts, C. R., Cruickshanks, K. J., Klein, B. E. K., Klein, R., \& Nondahl, D. M. (2002). Prevalence of olfactory impairment in older adults. Journal of Amercican Medical Association, 288(18), 2307-2312.

111. Nowlis, G. H., \& Kessen, W. (1976). Human newborns differentiate differing concentrations of sucrose and glucose. Science, 191(4229), 865-866.

112. Olofsson, J.K., et al., Long-term episodic memory decline is associated with olfactory deficits only in carriers of ApoE-epsilon 4. Neuropsychologia, 2016. 85: p. 1-9.

113. Ponsen, M.M., et al., Idiopathic hyposmia as a preclinical sign of Parkinson's disease. Annals of Neurology, 2004. 56(2): p. 173-181.

114. Pouyet, V., Cuvelier, G., Benattar, L., \& Giboreau, A. (2015). Influence of flavour enhancement on food liking and consumption in older adults with poor, moderate or high cognitive status. Food Quality and Preference, 44(Supplement C), 119-129.

115. Proserpio, C.,De Graaf, C., Laureti, M., Pagliarini, E. \& Boesveldt, S. 2017. Impact of ambient odors on food intake, saliva production and appetite ratings. Physiology \& Behavior, 174, 35-41.

116. Rahayel, S., J. Frasnelli, and S. Joubert, The effect of Alzheimer's disease and Parkinson's disease on olfaction: A meta-analysis. Behavioural Brain Research, 2012. 231(1): p. 60-74.

117. Ramaekers, M. G., Boesveldt, S., Lakemond, C. M. M., Van Boekel, M. A. J. S., \& Luning, P. A. (2014). Odors: Appetizing or satiating Development of appetite during odor exposure over time. International Journal of Obesity, 38(5), 650-656.

118. Ramaekers, M. G., Luning, P. A., Ruijschop, R. M. A. J., Lakemond, C. M. M., Bult, J. H. F., Gort, G., \& van Boekel, M. A. J. S. (2014). Aroma exposure time and aroma concentration in relation to satiation. British Journal of Nutrition, 111(03), 554562. doi:doi:10.1017/S0007114513002729 
119. Rhodes, D. G. (2014). Vital signs: fruit and vegetable intake among childrenUnited States, 2003-2010. MMWR Morb Mortal Wkly Rep, 63(31), 671-676.

120. Roberts, R.O., et al., Association Between Olfactory Dysfunction and Amnestic Mild Cognitive Impairment and Alzheimer Disease Dementia. Jama Neurology, 2016. 73(1): p. 93-101.

121. Rogers, P. J., Hogenkamp, P. S., de Graaf, K., Higgs, S., Lluch, A., Ness, A. R., Mela, D. J. (2015). Does low-energy sweetener consumption affect energy intake and body weight? A systematic review, including meta-analyses, of the evidence from human and animal studies. International Journal of Obesity. doi:10.1038/ijo.2015.177

122. Rosenstein, D., \& Oster, H. (1988). Differential facial responses to four basic tastes in new-borns. Child development, 1555-1568.

123. Ruijschop, R. M. A. J., Boelrijk, A. E., Burgering, M. J., de Graaf, C., \& Westerterp-Plantenga, M. S. (2010). Acute effects of complexity in aroma composition on satiation and food intake. Chemical Senses, 35(2), 91-100. doi:10.1093/chemse/bjp086

124. Ruijschop, R. M. A. J., Boelrijk, A. E., de Ru, J. A., de Graaf, C., \& WesterterpPlantenga, M. S. (2008). Effects of retro-nasal aroma release on satiation. Br J Nutr, 99(5), 1140-1148. doi:10.1017/s0007114507837482

125. Sakai, M., et al., Decline of gustatory sensitivity with the progression of Alzheimer's disease. International Psychogeriatrics, 2016. 28(3): p. 511-517.

126. Schiffman, S. S. (1991). Drugs influencing taste and smell perception. In T. V. Getchell, R. L. Doty, L. M. Bartoshuk \& J. B. Snow, Smell and taste in health and disease. New York: Raven Press.

127. Schiffman, S. S., \& Warwick, Z. S. (1993). Effect of flavour enhancement of foods for the elderly on nutritional status: food intake, biochemical indices and anthropometric measures. Physiology \& Behavior, 53, 395-402.

128. Schubert, C. R., Cruickshanks, K. J., Fischer, M. E., Huang, G. H., Klein, B. E. K., Klein, R., Pankow, J. S., \& Nondahl, D. M. (2012). Olfactory Impairment in an Adult Population: The Beaver Dam Offspring Study. Chemical Senses, 37(4), 325-334.

129. Sheard, J.M., et al., (2011). Prevalence of malnutrition in Parkinson's disease: a systematic review. Nutrition Reviews 69(9): p. 520-32. 
130. Skinner, J. D., Carruth, B. R., Bounds, W., Ziegler, P., \& Reidy, K. (2002). Do food-related experiences in the first 2 years of life predict dietary variety in school-aged children? Journal of Nutrition Education and Behavior, 34(6), 310-315.

131. Sorensen, L. B., Moller, P., Flint, A., Martens, M., \& Raben, A. (2003). Effect of sensory perception of foods on appetite and food intake: a review of studies on humans. Int J Obes Relat Metab Disord, 27(10), 1152-1166.

132. Stanciu, I., et al., Olfactory Impairment and Subjective Olfactory Complaints Independently Predict Conversion to Dementia. Chemical Senses, 2015. 40(3): p. 260260.

133. Stein, L. J., Cowart, B. J., \& Beauchamp, G. K. (2012). The development of salty taste acceptance is related to dietary experience in human infants: a prospective study. The American Journal of Clinical Nutrition, 95(1), 123-129.

134. Steinbach, S., et al., (2009). Qualitative and Quantitative Assessment of Taste and Smell Changes in Patients Undergoing Chemotherapy for Breast Cancer or Gynecologic Malignancies. Journal of Clinical Oncology, 27(11): p. 1899-1905.

135. Steinbach, S., et al., Taste in mild cognitive impairment and Alzheimer's disease. Journal of Neurology, 2010. 257(2): p. 238-246.

136. Steiner, J. E., Glaser, D., Hawilo, M. E., \& Berridge, K. C. (2001). Comparative expression of hedonic impact: affective reactions to taste by human infants and other primates. Neuroscience \& Biobehavioral Reviews, 25(1), 53-74.

137. Stevens, J. C., \& Dadarwala, A. D. (1993). Variability of olfactory threshold and its role in assessment of aging. Perception \& Psychophysics, 54(3), 296-302.

138. Stevens, J. C., Bartoshuk, L. M., \& Cain, W. S. (1984). Chemical senses and aging: taste versus smell. Chemical Senses, 9(2), 167-179.

139. Stevens, J. C., Cain, W. S., \& Demarque, A. (1990). Memory and identification of simulated odors in elderly and young persons. Bulletin of the Psychonomic Society, 28(4), 293-296.

140. Stevens, J. C., Plantinga, A., \& Cain, W. S. (1982). Reduction of odor and nasal pungency associated with aging. Neurobiology of Aging, 3(2), 125-132. 
141. Stewart, R., et al., (2005). A 32-year prospective study of change in body weight and incident dementia - The Honolulu-Asia aging study. Archives of Neurology, 62(1): p. $55-60$.

142. Sullivan, S. A., \& Birch, L. L. (1990). Pass the sugar, pass the salt: Experience dictates preference. Developmental psychology, 26(4), 546.

143. Sulmont-Rossé, C., Maître, I., \& Issanchou, S. (2010). Âge, perception chimiosensorielle et préférences alimentaires. Gérontologie et Société : Cahiers de la Fondation Nationale de Gérontologie, 134, 87-106.

144. Sulmont-Rossé, C., Maitre, I., Amand, M., Symoneaux, R., Van Wymelbeke, V., Caumon, E., Tavares, J., \& Issanchou, S. (2015). Evidence for different patterns of chemosensory alterations in the elderly population: impact of age versus dependency. Chemical Senses, 40(3), 153-164.

145. Sulmont-Rossé, C., Symoneaux, R., Feyen, V., \& Maître, I. (in press). Improving food sensory quality with and for elderly consumers. In G. Ares \& P. A. Varela Tomasco, Methods in Consumer Research Volume 2: Alternative Approaches and Special Applications. Amsterdam, The Netherlands: Elsevier.

146. Sylvetsky, A. C., Welsh, J. A., Brown, R. J., \& Vos, M. B. (2012). Low-calorie sweetener consumption is increasing in the United States. The American Journal of Clinical Nutrition, 96(3), 640-646.

147. Tetley, A., Brunstrom, J., \& Griffiths, P. (2009). Individual differences in foodcue reactivity. The role of BMI and everyday portion-size selections. Appetite, 52(3), 614-620. doi:http://dx.doi.org/10.1016/j.appet.2009.02.005.

148. Thomas-Danguin, T., Rouby, C., Sicard, G., Vigouroux, M., Farget, V., Johansson, A., Bengtzon, A., Hall, G., Ormel, W., de Graaf, C., Rousseau, F., \& Dumont, J. P. (2003). Development of the ETOC: a European test of olfactory capabilities. Rhinology, 41(3), 142-151.

149. Toussaint, N., de Roon, M., van Campen, J.P.C.M., Kremer, S., Boesveldt, S. Loss of Olfactory Function and Nutritional Status in Vital Older Adults and Geriatric Patients. Chemical Senses, 2015. 40(3): p. 197-203.

150. van der Marck, M.A., et al., Body mass index in Parkinson's disease: a metaanalysis. Parkinsonism Relat Disord, 2012. 18(3): p. 263-7. 
151. Vandenberghe-Descamps, M., Labouré, H., Prot, A., Septier, C., Tournier, C., Feron, G., \& Sulmont-Rossé, C. (2016). Salivary flow decreases in healthy elderly people independently of dental status and drug intake. Journal of Texture Studies, 47, 353-360.

152. Vickers, Z., \& Holton, E. (1998). A comparison of the taste test ratings, repeated consumption, and post-consumption ratings of different strength iced tea. Journal of Sensory Studies, 13(2), 199-212. doi:10.1111/j.1745-459X.1998.tb00083.x

153. Vickers, Z., Holton, E., \& Wang, J. (2001). Effect of ideal-relative sweetness on yogurt consumption. Food Quality and Preference, 12(8), 521-526. doi:http://dx.doi.org/10.1016/S0950-3293(01)00047-7.

154. Viskaal-van Dongen, M., Kok, F. J., \& de Graaf, C. (2011). Eating rate of commonly consumed foods promotes food and energy intake. Appetite, 56(1), 25-31.

155. Werthmann, J., Jansen, A., Havermans, R., Nederkoorn, C., Kremers, S., \& Roefs, A. (2015). Bits and pieces. Food texture influences food acceptance in young children. Appetite, 84, 181-187.

156. Yeomans, M. R. (1998). Taste, palatability and the control of appetite. Proceedings of the Nutrition Society, 57(04), 609-615. doi:doi:10.1079/PNS19980089

157. Zabernigg, A., Gamper, E.-M., Giesinger, J.M. Rumpold, G., Kemmler, G. Gattringer, K., Sperner-Unterweger, B. \& Holzner, B. (2010). Taste Alterations in Cancer Patients Receiving Chemotherapy: A Neglected Side Effect? Oncologist, 15(8): p. 913920.

158. Zhu, Y., Hsu, W. H., \& Hollis, J. H. (2013). The Impact of Food Viscosity on Eating Rate, Subjective Appetite, Glycemic Response and Gastric Emptying Rate. PLos One, 8(6), e67482. doi:10.1371/journal.pone.0067482

159. Zijlstra, N., de Wijk, R. A., Mars, M., Stafleu, A., \& de Graaf, C. (2009). Effect of bite size and oral processing time of a semisolid food on satiation. American Journal of Clinical Nutrition, 90(2), 269-275.

160. Zijlstra, N., Mars, M., de Wijk, R. A., Westerterp-Plantenga, M. S., \& de Graaf, C. (2008). The effect of viscosity on ad libitum food intake. International Journal of Obesity, 32(4), 676-683. 
161. Zijlstra, N., Mars, M., de Wijk, R. A., Westerterp-Plantenga, M. S., Holst, J. J., \& de Graaf, C. (2009). Effect of viscosity on appetite and gastro-intestinal hormones. Physiology \& Behavior, 97(1), 68-75.

162. Zoon, H. F. A., He, W., de Wijk, R. A., de Graaf, C., \& Boesveldt, S. (2014). Food preference and intake in response to ambient odours in overweight and normalweight females. Physiology \& Behavior, 133, 190-196.

163. Zoon, H. F., DeGraaf, C. \& Boesveldt, S. (2016). Food odours direct specific appetite. Foods, 5, 12. 


\section{Figure and Table Captions:}

Figure 1. Representation of the different factors liable to have an impact on olfactory capacities in the elderly

Table 1: Review of studies on the impact of flavour enhancement on food intake in elderly people 